\title{
Os Desafios da Narrativa Digital e Cinema em Sala de Aula
}

\author{
Rosmeri Ceconi $^{1}$ Vanessa Orsi $^{1}$ \\ ${ }^{1}$ Escola Municipal de Ensino Fundamental 29 de Setembro - Dois Irmãos, RS. \\ rosmericeconi@gmail.com vanessaorsi86@gmail.com
}

\begin{abstract}
Abstract: This article presents a project conducted in the first half of 2014 with 8th and 9th graders, performed by the Informatics and Portuguese teachers in a municipal Elementary School. It is an innovative project for the school and for the students, given that it is an interdisciplinary work that goes beyond classroom limits and uses technology as an ally in the construction of knowledge. The project comes down to the production of short films and it involved several different activities to obtain the final product.

Resumo: O presente artigo apresenta um projeto realizado no primeiro semestre de 2014 com alunos do $8^{\circ}$ e $9^{\circ}$ anos, pelas professoras de Informática e de Português de uma escola municipal de Ensino Fundamental. Trata-se de um projeto inovador para a escola e para os alunos, tendo em vista que é um trabalho interdisciplinar que extrapola os limites da sala de aula e utiliza a tecnologia como aliada na construção do conhecimento. O projeto resume-se à produção de curtas-metragens e envolveu diversas atividades para obtenção do produto final.
\end{abstract}

\section{Introdução}

Atualmente, nossos alunos têm acesso a todos os tipos de mídias. Clipes, documentários e os mais variados filmes estão disponíveis e podem ser baixados da internet com muita facilidade.

Trazer este tema para trabalhar com os alunos em sala de aula é um desafio muito grande porque não se tem, na formação pedagógica, referencial voltado à produção de material, e, ao mesmo tempo, os alunos não se apropriam dos conhecimentos como deveriam, pois eles estão muito distantes da sua realidade.

Pensando nisso, surgiu a ideia de trabalhar com a narrativa digital, uma ferramenta interativa que desenvolve a escrita, a leitura e a compreensão textual de uma forma envolvente e significativa. Nesse gênero textual, os elementos básicos da narrativa (enredo, narrador, personagens, tempo e espaço) ganham significados para os alunos, que conseguem vincular o conteúdo ao mundo digital.

Como diz Carvalho (2008):

"A construção e produção de narrativas digitais constituemse num processo de produção textual que assume o carácter contemporâneo dos recursos audiovisuais e tecnológicos capazes de modernizar 'o contar histórias', tornando-se uma ferramenta pedagógica eficiente e motivadora ao aluno, ao mesmo tempo em que agrega à prática docente o viés da inserção da realidade tão cobrada em práticas educativas." 
Os alunos, atualmente, veem a escola como algo chato, sem graça e sentem-se desmotivados para a maioria dos trabalhos propostos em sala de aula. A expressão, tanto oral como escrita, é uma habilidade muito importante a ser desenvolvida, no entanto é uma tarefa árdua para os professores encontrar formas de motivar os alunos para a produção. Motivadas por este desafio de transformar e atualizar a escrita e a produção oral, sem perder suas raízes, nos propomos a, junto com os alunos, descobrir como se faz cinema e o que está por trás de um clipe do Youtube, por exemplo.

Usar a Narrativa Digital em sala de aula, como ferramenta de Ensino e Aprendizagem, além de levar o aluno a produzir, sendo autor e construtor de conhecimento, amplia a visão de mundo, possibilitando, inclusive, que se descubram talentos que o ensino tradicional jamais revelaria. Com esse tipo de trabalho o aluno passa a ter uma visão mais crítica sobre as mídias, pois ao tomar conhecimento de como são produzidos e dos recursos utilizados para despertar o interesse de quem assiste, ele deixa de ser um espectador passivo.

\section{Contexto do trabalho}

A escola onde o trabalho foi realizado atende, atualmente, 230 alunos, dos quais a grande maioria provém de um dos bairros mais carentes do município. Os pais trabalham na indústria calçadista e o seu grau de instrução é muito baixo, o que acaba gerando um sentimento de que não é tão importante ter estudo ou uma profissionalização. Os alunos vêm para a escola com uma autoestima baixa e pouca perspectiva de melhorar a sua condição de vida. A escola, para muitos, é apenas um lugar onde são obrigados a frequentar, ou pelos pais ou pelo Conselho Tutelar.

Este trabalho, além de ter os objetivos específicos das disciplinas e contemplar as habilidades previstas para a área, pretende ser um instrumento para ampliar a visão de mundo dos alunos, oportunizando a eles um olhar mais crítico sobre os filmes que assistem e despertando o surgimento de talentos na área da produção audiovisual.

\section{Organização para realização do projeto}

A organização para a realização do projeto envolve a reflexão a respeito de todos os aspectos relacionados à execução e desenvolvimento, inclusive aos conteúdos curriculares a serem abordados. Neste aspecto o trabalho foge dos tradicionais conteúdos do plano de curso da Língua Portuguesa e/ou Informática. A intenção é, justamente, ampliar a visão de mundo do aluno introduzindo assuntos que não fazem parte do currículo oficial. No entanto, as habilidades e competências trabalhadas durante o projeto extrapolam as possibilidades dos conteúdos curriculares obrigatórios.

Foi necessário pensar em como se daria o trabalho em relação ao tempo e às aulas que seriam usadas para o desenvolvimento do projeto. Optou-se em usar uma aula de português, uma vez por semana, com duração de 50 minutos. Outro aspecto importante da organização foi a escolha dos materiais de referência, considerando a 
pouca experiência das professoras no assunto e pouca disponibilidade de material teórico para o nível do Ensino Fundamental.

Como o tema do curta produzido pelos alunos era de livre escolha, podem-se citar como conteúdos trabalhados: formas de comunicação e expressão, produção textual (pontuação, ortografia, coesão e coerência textual, adequação vocabular, gênero textual "roteiro", narrativa digital), história do cinema, gêneros cinematográficos e a linguagem cinematográfica. Além disso, podem-se citar as ferramentas da tecnologia que foram utilizadas no projeto, como: Blog, apresentação eletrônica e software para edição do vídeo.

\section{Metodologia}

O projeto foi desenvolvido em conjunto pelas professoras de Informática e Português com as turmas do $8^{\circ}$ e $9^{\circ}$ anos, nas aulas de Língua portuguesa. Foi criado um blog com o objetivo de registrar todo o processo do desenvolvimento, bem como as dificuldades encontradas pelos alunos na realização do mesmo. O Blog serviu como referência durante todo projeto para alunos e professores, reforçando a ideia de registro e publicação de conteúdo e de compartilhamento de informações. Todas as instruções sobre as atividades a serem desenvolvidas e as produções dos alunos eram registradas no Blog. O uso do Blog, por si só, já representa uma inovação metodológica, pois é um registro público que muda a motivação da produção escrita por parte dos alunos. Ao saber que escrevem para um público diferenciado, produzem com mais motivação do que aquela empregada ao escrever um texto para o professor. A seguir serão detalhadas as etapas do desenvolvimento do projeto.

Para Gabriel

“(...)o uso de tecnologias em sala de aula não é apenas um instrumento para ler melhor, mas para pensar, criar, imaginar, comunicar, simular e extrapolar as possibilidades do mundo físico. $\mathrm{O}$ nosso cérebro conectado a esse arsenal tecnológico se amplia consideravelmente, nos tornando cíbridos (híbridos de ciberespaço e corpo biológico) conectados" (GABRIEL 2013).

\subsection{Conhecendo mais sobre Cinema.}

"Apreender o que os filmes dizem e o que cada espectador, ao ver o filme, quer dizer, talvez seja a experiência educativa mais profunda que o cinema possa proporcionar. Cinema pode ensinar, para muito além do conteúdo que os filmes parecem apresentar à primeira vista. (COUTINHO, 2005).

Todos nós gostamos de assistir um bom filme. Todos nós temos conceitos construídos sobre cinema, filme, tipos de filmes e outros, no entanto, pouco conhecimento temos acerca da produção cinematográfica. Ao iniciar o projeto, a primeira preocupação era fornecer elementos aos alunos para que estes tivessem uma visão mais ampla do tema, por isso foi importante trabalhar um pouco mais sobre a linguagem audiovisual, desde 
sua origem, com os primeiros filmes, até as produções mais recentes. Neste sentido, foram exibidos documentários que auxiliaram no entendimento de como se iniciou a produção cinematográfica. O debate sobre os documentários possibilitou que cada um dos atores envolvidos destacasse suas impressões, as quais foram registradas no Blog do projeto.

Ainda para ilustrar a evolução do cinema e fazer uma comparação com o que hoje existe em termos de cinema foi exibido o filme "A Cura", de Charles Chaplin, como um exemplo de cinema mudo e sem cores. Muitos alunos nunca tinham assistido a este tipo de filme e não tinham noção do quanto já se avançou com a tecnologia na produção cinematográfica.

Nesta etapa, ainda, os alunos conheceram outros projetos de produção cinematográfica feita por alunos. Foram vistos alguns filmes disponíveis no site do portal Nuvem TV como exemplo de vídeos produzidos por alunos de diversos lugares do Brasil.

Outro site visitado foi do Cineasta Professor Carlos Gerbase, Meu primeiro filme. Lá também encontramos vídeos produzidos por alunos. Os alunos eram orientados a assistir aos vídeos pensando em que gostariam de fazer, em que tipo de filme gostariam de produzir. Acessar os vídeos feitos por outros alunos foi importante para que percebessem que é possível produzir um filme com poucos recursos, que qualquer um que tiver uma boa história e uma câmera pode fazer um filme.

\subsection{Apropriação da linguagem audiovisual.}

Para que possamos escrever um texto é necessário que conheçamos a gramática da Língua Portuguesa. O mesmo acontece para filmar. No lugar de palavras, há planos, mas a noção de ritmo é a mesma. Os planos de um filme podem ser curtos ou longos, assim como as frases de um livro. Teleobjetiva, grande angular, câmera na mão. Onde o diretor posiciona a câmera? O que é decidido na pré-produção, o que se deixa para a filmagem e o quão aberto se leva o material para a montagem? Como integrar o trabalho de câmera com o trabalho dos atores? Não há respostas únicas para essas perguntas. Tudo depende do método do diretor.

No contexto da educação para as mídias, a produção não é um fim em si. Os jovens se apropriam da linguagem midiática para expressar suas ideias e sentimentos de forma criativa ou por meio da Arte. Usam a mídia para comunicação, sem reduzir esse fazer a um treinamento técnico. Há também a preocupação em compreender a linguagem audiovisual, não como um sistema fechado, mas processual, por meio do qual são construídas as representações e onde acontecem interações. $\mathrm{O}$ aluno é visto como sujeito histórico, social e cultural, e não apenas como interlocutor, mas como sujeito criativo, transformador. Neste sentido, foi importante os alunos apropriarem-se dos principais conceitos sobre a produção de cinema. Foram realizadas pesquisas na internet sobre os gêneros cinematográficos existentes, como: Documentário, Entrevista, Animação e filme (ficção, romance, terror, suspense, comédia e outros). Com a supervisão das professoras, em duplas, os alunos criaram apresentações eletrônicas sobre os gêneros cinematográficos, contendo uma pequena explicação e exemplos de filmes daquele gênero. Foram fornecidos alguns links para que os alunos pudessem pesquisar, evitando desta forma, a dispersão, pois a internet oferece uma quantidade muito grande de possibilidades de pesquisa. 
Além disso, foi necessário apropriar-se das fases de produção de um filme como: criação do roteiro, levantamento de custos (orçamento), escolha do elenco, agendamento de locais, equipamentos cinematográficos, figurino, objetos e utilitários de cena, pré-ensaio, preparação do cenário, ação, sonoplastia ou fundo musical e montagem.

Além da pesquisa, os alunos assistiram uma entrevista do Professor Cineasta Garlos Gerbase, da PUCRS - Porto Alegre, sobre produção do seu primeiro filme. Em seguida, produziram uma apresentação eletrônica onde descreveram cada etapa da produção de um filme e tudo que envolve cada uma.

\subsection{Definição das tarefas}

Nesta etapa os alunos formaram os grupos de trabalho. Até este momento os trabalhos eram feitos individualmente ou em duplas. A partir deste ponto formaram grupos, que trabalhariam juntos até o final do projeto. Foram definidas quais eram as tarefas de cada integrante do grupo, considerando tudo o que envolve a produção de um filme.

Os grupos foram formados por afinidade. As tarefas começaram a ser definidas de acordo com o que cada um mais se identificava. Isso fez com que cada um assumisse uma tarefa e ficasse responsável pela mesma. Percebeu-se neste momento o quanto estavam envolvidos no trabalho, pois na divisão de tarefas já começaram a preocupar-se com o que deveriam fazer. A responsabilidade com a tarefa assumida é um aspecto muito importante no sucesso do trabalho. Então, além dos conhecimentos construídos com o desenvolvimento do projeto trabalha-se com habilidades importantes para a vida do aluno, como o comprometimento e a responsabilidade. Nas negociações entre professor e aluno os sujeitos aprendem a pensar o "eu" e o "outro", num processo interativo, aproximando, justapondo os contrários, situando o olhar nas fronteiras. Nesse contexto, a produção audiovisual nos espaços escolares nos remete ao pensamento de que vivemos um momento histórico em que a mídia eletrônica deveria ser encarada - ao contrário daquilo que muitos discursos apocalípticos pregam - como um fato da cultura, que exprime nossa complexidade e nossas contradições.

\subsection{Criação do roteiro}

Todo roteiro - assim como toda obra literária e toda obra de arte - começa sempre a partir de uma ideia. A criatividade pode ser alimentada pela observação e interpretação da realidade, através da leitura, pesquisa e vivências do próprio autor. O importante é que cada um desenvolva seu próprio processo criativo. Para desenvolver a criatividade e auxiliar na escrita, foram proporcionadas oficinas de criação de roteiro. Por meio de vídeo conferência tivemos o auxílio de uma roteirista profissional. Foram realizados diversos exercícios de escrita com o objetivo de "soltar a imaginação", como: Criação e caracterização de personagem, incorporação de elementos como a hipótese fantástica transformação de objetos, sem vida própria, em personagens da história. Além disso, na oficina, foram trabalhadas as questões de áudio presentes num vídeo, considerando que cada som remete a uma imagem. O áudio ajuda a contar a história. Foi importante que os alunos percebessem que existe uma linguagem cinematográfica que nada mais é do 
que recursos que são utilizados pelos cineastas para ajudar a reforçar a ideia que se quer passar com o filme.

Depois das oficinas realizadas os alunos iniciaram a escrita do roteiro. Primeiro foi escrita e apresentada apenas a sinopse do filme e, em seguida, iniciou-se a escrita detalhada do roteiro, cena por cena, contendo falas e áudio.

Neste momento cabe ressaltar também que os alunos do $9^{\circ}$ ano transpassaram as barreiras da escrita e, após terem realizado um trabalho sobre crônicas em sala de aula, decidiram dar voz às suas produções, transformando-as em roteiros. Os seus curtas, então, foram baseados nas crônicas que desenvolveram em aula.

Assim que os alunos terminavam a escrita, entregavam para professora de Língua Portuguesa que analisava e solicitava reescrita, caso fosse necessário.

Este tipo de produção textual é prazerosa ao aluno, uma vez que ele está produzindo um texto que não ficará restrito ao papel. A produção textual ganha, com isso, significação e objetivos claros e torna-se um momento lúdico e importante, já que com ela se registrará um trabalho tão significativo para os alunos.

Além da escrita do roteiro havia a questão da organização para filmagem. Foi estabelecido um cronograma de datas e locais para as filmagens e feito um "checklist" com tudo que precisava ser pensado e organizado antes de inicia-la.

\subsection{Produção}

Chamamos produção o início das filmagens propriamente ditas, que pressupõe que todos (ou pelo menos a grande maioria) dos itens da pré-produção já estejam resolvidos.

A produção confunde-se com a própria ação de fazer cinema, mas este fazer cinema inclui muito mais que o set de filmagem. De qualquer maneira, esta é a etapa mais sedutora do trabalho em cinema.

Com o roteiro na mão, iniciaram as filmagens. Como os alunos tiveram diversas aulas em que foi tratado sobre a linguagem cinematográfica, foi mais fácil realizá-las. Os cuidados com a câmera, com a captura do áudio, com a iluminação do local da filmagem, cada detalhe recebeu um olhar atento. Percebeu-se que os alunos estavam cuidadosos com todos estes detalhes, o que fez com que a qualidade do material produzido fosse muito boa. Durante as filmagens cada um assumiu seu papel, responsabilizando-se por aquilo que lhe foi destinado como tarefa. Nesta etapa do trabalho pode-se perceber que além de todo o conhecimento que os alunos estavam construindo, outras habilidades eram trabalhadas, como: responsabilidade, comprometimento, coleguismo, entre outros. Por vezes aconteciam desentendimentos entre o grupo e este é outro aspecto a ser considerado neste tipo de trabalho. O grupo precisa dar-se conta de que precisam trabalhar unidos e organizados para que tudo funcione.

\subsection{Finalização e montagem}

A edição do vídeo representou a etapa de maior desafio para todos, pois nesta estapa os alunos fizeram a montagem e sonorização do filme. Foi utilizado um programa 
proprietário que permite editar as cenas captadas e adicionar ou retirar áudio. Esta finalização do filme representou outros ganhos de conhecimento muito importantes para os alunos. Esta geração tem muita facilidade de lidar com as tecnologias, no entanto são apenas consumidores, não sabem usar a tecnologia para produzir e este foi um dos principais benefícios desta etapa do projeto. Aprender a utilizar um software, editar e produzir um vídeo foi muito importante para os alunos, pois passam de meros utilizadores da tecnologia a produtores da mesma.

\subsection{Exibição e avaliação}

Nesta etapa todos os alunos puderam assistir aos vídeos produzidos durante o projeto. Percebe-se que adquiriram um senso crítico muito interessante. Os comentários feitos traduzem os conhecimentos construídos durante o projeto. Além de conseguir ampliar seus conhecimentos nunca mais irão assistir a um filme com os mesmos olhos. Os alunos que não participaram do projeto demonstraram interesse em participar e incentivaram muito os produtores com elogios.

\section{5 .Resultados e Discussão}

Como resultados deste trabalho pode se destacar que:

- A grande maioria dos alunos estava envolvida e comprometida com o trabalho durante todo o desenvolvimento do projeto. Em alguns momentos foi necessário resgatar um ou outro por desmotivação ou desentendimento com o grupo, mas, como resultado, pode-se dizer que foi muito positiva a participação do grupo de alunos;

- O projeto contribuiu para construir valores como responsabilidade e comprometimento;

- Em relação à aprendizagem é possível afirmar que o projeto contribuiu no sentido de resgatar o prazer em estar na escola, pois era visível a empolgação dos alunos nas atividades relacionadas ao projeto;

- É possível afirmar, ainda, que o projeto contribuiu para melhorar a criatividade na escrita dos textos, melhorar a organização dos textos, melhorar até mesmo a motivação para a escrita. O objetivo de encontrar formas diversificadas de trabalhar a expressão foi atingido.

- O trabalho proporcionou aos alunos construir conhecimentos e adquirir habilidades ligadas às tecnologias digitais, ampliando seu leque de possibilidades de uso, deixando de serem meros consumidores.

- Em relação ao cinema, construíram um olhar crítico que lhes possibilita assistir um filme com um olhar crítico.

- Aos professores possibilitou uma mudança na prática pedagógica, desacomodou e obrigou a buscar e pesquisar por temas ligados ao projeto. Representou uma oportunidade de construção de conhecimento, pois foi necessário buscar um curso para auxiliar os alunos na parte da edição dos filmes. Além disso, também ampliou a visão crítica acerca da linguagem cinematográfica. 
- Representou, ainda, uma mudança na prática avaliativa. A avaliação foi realizada durante todo o desenvolvimento do projeto, iniciando com o diagnóstico sobre os conhecimentos que os alunos possuíam. Diversas atividades foram desenvolvidas e em cada uma delas a avaliação se dava forma diferenciada. Foram consideradas a participação, o envolvimento, comprometimento e dedicação de cada estudante durante os trabalhos, identificando se os conhecimentos que possuíam antes do projeto se ampliaram, além da produção textual: roteiro. Também foi avaliado o desempenho dos estudantes durante as discussões e a capacidade de argumentação, além da coerência e da coesão nos textos e apresentações elaboradas pelas equipes e no filme apresentado.

\section{Conclusões}

A culminância do projeto deu-se com a produção dos curtas-metragens pelos alunos. Para que chegassem a isso foi necessário estimular a sua criatividade com técnicas que os levassem a escrever o roteiro e tudo que envolve a sua produção, desenvolvendo habilidades que a escrita de uma redação convencional não desenvolveria, tendo em vista que "as tecnologias digitais não são apenas uma nova forma de fazer as mesmas coisas (como ler), mas também e, principalmente, de fazer coisas novas"(GABRIEL 2013).

Realizar este trabalho foi muito bom para nós enquanto professoras. Em primeiro lugar foi muito prazeroso, pois nada é mais gratificante que ver o aluno empenhado, envolvido, produzindo e construindo conhecimento. Claro que, ainda assim, alguns alunos não estavam tão empenhados e com estes foi necessário fazer um acompanhamento mais de perto, foi necessário auxiliá-los dando dicas sobre o que e como poderiam fazer. É neste momento que o trabalho do professor faz a diferença, pois é preciso resgatar os alunos que menos trabalham trazendo-os de volta para motivação.

Com este trabalho, nós, professoras também construímos conhecimentos novos, pois foi necessário estudar e buscar recursos teóricos para poder auxiliar os alunos: primeiro um trabalho de pesquisa aprofundada sobre produção cinematográfica e depois saber operar um software de edição de vídeos.

Representou um ganho pessoal na medida em que nós também não vamos mais assistir um filme com os mesmos olhos. Conhecemos tudo o que está por detrás da produção deste filme. Passamos a entender alguns truques utilizados para ajudar a contar a história do filme. Enfim, compreendemos melhor a linguagem cinematográfica.

Consideramos o projeto uma oportunidade de ampliar a visão de mundo do aluno, saindo da sala de aula e dos tradicionais conteúdos curriculares, com o uso das Tecnologias Digitais.

Os objetivos deste projeto eram motivar os alunos para a produção e construção de conhecimento usando as tecnologias digitais, encontrar formas diferenciadas e variadas de usar a expressão oral e escrita e levar os alunos a produzir um curta-metragem.

Pode-se concluir que o projeto atingiu os objetivos propostos pelos resultados apresentados e pelo retorno positivo que gerou em termos de aprendizagem e envolvimento de todos os atores do projeto. Também para a escola como um todo gerou 
um resultado positivo, pois o trabalho foi comentado entre alunos e professores estimulando a continuidade do mesmo, e permitindo que, talvez, se descubram talentos entre os alunos e que estes possam até, quem sabe, serem futuros cineastas, roteiristas ou ocupar qualquer outra função que envolve a produção cinematográfica.

Enfim, este está sendo um trabalho desafiador, em que o próprio professor precisa ir em busca de conhecimentos e atualizações para receber em troca muitas aprendizagens e reavivar o brilho nos olhos que provoca o aprender, tão desmistificado no cenário atual.

\section{Referências Bibliográficas}

CARVAlHO, G. S. As Histórias Digitais: Narrativas no Século XXI. Universidade de São Paulo. São Paulo, 2008.

COUTINHO, L. Refletindo sobre a linguagem do cinema, 2005.

GABRIEL, Martha . Educação em revista. No 101, ano XVII, Novembro e Dezembro 2013.

GERBASE, Carlos. Cinema: Primeiro Filme: descobrindo, fazendo, pensando. Porto Alegre: Artes e Ofícios, 2012.

Links de referência utilizados durante o Projeto:

As origens do cinema: http://www.youtube.com/watch?v=f7JQvgYLkg8\&feature=related

A invenção do cinema https://www.youtube.com/watch?v=tkkl7_oDxXU

Plano de aula: http://revistaescola.abril.com.br/fundamental-2/plano-de-auladesenvolvimento-tv-online-731566.shtml

Cinema une Arte e Informática: http://revistaescola.abril.com.br/arte/praticapedagogica/cinema-une-arte-informatica-424909.shtml

Filmes de alunos: http://www.nuvem.tv/?p=inicio

Meu Primeiro Filme: http://www.primeirofilme.com.br/site/o-festival/filmesparticipantes/.

Cinema em etapas: http://cineastassemdiploma.blogspot.com.br/ 